\title{
Gene expression levels of the insulin-like growth factor family in patients with AMD before and after ranibizumab intravitreal injections
}

This article was published in the following Dove Press journal:

Clinical Interventions in Aging

5 September 2017

Number of times this article has been viewed

\author{
Barbara Strzalka-Mrozik' \\ Malgorzata Kimsa-Furdzik ${ }^{2}$ \\ Adam Kabiesz ${ }^{3}$ \\ Katarzyna Michalska- \\ Malecka ${ }^{3,4}$ \\ Malgorzata $\mathrm{Nita}^{5}$ \\ Urszula Mazurek'
}

'Department of Molecular Biology, School of Pharmacy with the Division of Laboratory Medicine in Sosnowiec, Medical University of Silesia, Katowice, Poland; ${ }^{2}$ Department of Biochemistry, School of Medicine in Katowice, Medical University of Silesia, Katowice, Poland; ${ }^{3}$ University Center for Ophthalmology and Oncology, Independent Public Clinical Hospital, Medical University of Silesia, Katowice, Poland; ${ }^{4}$ Department of Ophthalmology, School of Medicine in Katowice, Medical University of Silesia, Katowice, Poland; ${ }^{5}$ Domestic and Specialized Medicine Centre "Dilmed", Katowice, Poland
Correspondence: Barbara

Strzalka-Mrozik

Department of Molecular Biology,

School of Pharmacy with the Division of Laboratory Medicine in Sosnowiec, Medical University of Silesia, Katowice, Poland, Jednosci 8, 4I-200 Sosnowiec, Poland

Tel +48 323641026

Fax +4832364I020

Email bstrzalka@sum.edu.pl
Purpose: The present study focused on the assessment of the mRNA levels of the insulin-like growth factor (IGF) family in patients with the exudative form of age-related macular degeneration (AMD) before and after ranibizumab intravitreal injections.

Patients and methods: An analysis of the expression profile of the IGF family of genes in patients with AMD was carried out using the oligonucleotide microarray and quantitative reverse transcriptase polymerase chain reaction (RT-qPCR) methods.

Results: In the peripheral blood mononuclear cells (PBMCs) obtained from AMD group receiving ranibizumab compared to the peripheral blood mononuclear cells from AMD group before ranibizumab treatment using oligonucleotide microarray technique, six statistically significant differentially expressed transcripts related to the IGF family were detected (unpaired $t$-test, $p<0.05$, fold change $>1.5$ ). Moreover, analysis using the real-time RT-qPCR technique revealed statistically significant differences in the IGF2 and IGF2R mRNA levels (MannWhitney $U$ test, $p<0.05$ ) between the two groups that were studied. Statistical analyses of both oligonucleotide microarray and real-time RT-qPCR results demonstrated a significant decreased expression only for IGF2 mRNA.

Conclusion: Our results revealed a changed expression of IGF2 mRNA after ranibizumab treatment.

Keywords: age-related macular degeneration, IGF family, ranibizumab, mRNA

\section{Introduction}

Age-related macular degeneration (AMD) is a chronic, progressive disease that leads to permanent physiological and morphological changes in the retina and therefore leads to the irreparable impairment of the visual acuity. AMD is one of the most frequent causes of blindness in the population over 50 years of age in developed countries. ${ }^{1-4}$ Moreover, a poor prognosis of visual outcomes in untreated cases was confirmed. ${ }^{5}$ Although it is believed that various genetic and environmental factors may have a significant impact on the development of AMD, the etiology of this complicated disease is still unknown. ${ }^{6,7}$

Insulin-like growth factors (IGFs) are essential for the regulation of cellular processes, such as differentiation, apoptosis, and neovascularization. ${ }^{8}$ It is well known that IGFs can stimulate the proliferation of endothelial cells. Moreover, they can activate the vascular endothelial growth factor (VEGF) expression. Therefore, they can participate in the pathogenesis of various diseases that are associated with pathological angiogenesis. ${ }^{9}$ Locally produced IGFs seem to be especially important in the 
development of ocular diseases such as AMD, diabetic retinopathy, or retinopathy of prematurity (ROP). ${ }^{10}$

The IGF family consists of two cell-surface receptors (IGF1R and IGF2R), two growth factor ligands (IGF1 and IGF2), six high-affinity IGF binding proteins (IGFBP1-6), and associated IGFBP degrading enzymes. ${ }^{11,12}$ Moreover, members of these growth factors include nine IGFBPrelated proteins, which can bind to the IGFs but with a lower affinity than IGFBPs. ${ }^{13}$ IGFs and IGFRs have amino acid sequences that are homologous to insulin or an insulin receptor, respectively. ${ }^{14}$

Ranibizumab (Lucentis; Novartis International AG, Basel, Switzerland) is an anti-VEGF agent that is commonly used in the form of intravitreal injections to treat the neovascular exudative type of AMD and choroidal neovascularization (CNV), which is secondary to many other reasons. ${ }^{15-17}$ The efficacy and safety of ranibizumab in the treatment of exudative AMD have been demonstrated in many previous studies including large samples studies and multicenter randomized clinical trials as well as in substantial clinical practice. ${ }^{15,18}$ However, systemic side effects of intraocular anti-VEGF therapy for AMD are posited. ${ }^{17,19}$ Moreover, gene expression or protein level changes in the blood samples of AMD patients after intravitreal anti-VEGF treatment are not well known. ${ }^{20-22}$ There are only a few data about the systemic expression profile of IGF-related genes in patients with ocular diseases or the influence of the antiVEGF drugs that are used in the treatment of these diseases on its change. ${ }^{23}$

Therefore, the present study focused on the assessment of the mRNA levels of the IGF genes in patients with the exudative form of AMD before and after ranibizumab intravitreal injection.

\section{Patients and methods Ethics statement}

Permission to conduct the study was obtained from the Bioethics Committee of the Medical University of Silesia in Katowice (KNW/0022/KB1/61/10 and KNW/0022/KB1/61/ II/10/12). All donors provided written informed consent in accordance with the Declaration of Helsinki. All of the patients were treated at the Department of Ophthalmology, University Hospital No 5, Medical University of Silesia, Katowice, Poland.

\section{Subjects}

Twenty-nine patients (15 women and 14 men, mean age 73 years, range 54-86 years) with diagnosed neovascular
AMD were enrolled into the study. All patients were subjected to the following ocular investigations: bestcorrected visual acuity using Snellen charts, Goldmann applanation tonometry, indirect biomicroscopy in mydriasis (+78 D lens; Volk Optical, Mentor, OH, USA), optical coherence tomography (OCT, Cirrus HD-OCT 4000; Carl Zeiss Meditec AG, Jena, Germany), and fluorescein angiography (Fundus Camera FF 450 plus IR; Carl Zeiss Meditec AG).

The study group was homogenous in terms of age, race, and gender and consisted of highly selected patients who had no other diseases except for hypertension, had no ophthalmic surgery, and had no stroke or myocardial infarction during the previous 6 months. The main inclusion criteria for the study group included: CNV resulting from AMD, aged $>50$ years, best-corrected visual acuity $0.1-0.5$ according to the Snellen chart, and no previous CNV therapies, such as anti-VEGF injections, photodynamic therapy, or laser therapies. The main exclusion criteria from the study group were as follows: uncontrolled, elevated intraocular pressure; glaucomatous optic neuropathy; chronic uveitis; retinal vein occlusion; other ocular neovascular diseases; and a previous history of myocardial infarction or stroke during the previous 6 months.

The time between first symptoms and ranibizumab injections was up to 3 months. Intravitreal injections were performed by an ophthalmologist who used an aseptic technique, using infiltration anesthesia at the injection site. Ranibizumab $(0.5 \mathrm{mg})$ was administered intravitreally three times in the form of one injection every month during a period of 3 months. The reinjections were dependent on the CNV activity.

\section{Tissues}

Venous blood samples $(5 \mathrm{~mL})$ for molecular analysis were obtained from the all AMD patients included in the study before ranibizumab injections and 30 days after the application of the three injections of ranibizumab at around the same time of day and collected into tubes containing EDTA. Isolation of peripheral blood mononuclear cells (PBMCs) was performed using the Ficoll-Conray density gradient centrifugation for 30 minutes at 1,500 rpm at room temperature immediately after blood collection (specific gravity 1.077; Immunobiological Co., Gunma, Japan).

\section{RNA extraction}

Total RNA extraction was performed using TRIzol reagent (Invitrogen Life Technologies, CA, USA) according to the 
producer's instructions. The purification, integrity, and quantitative assessment of the RNA extracts was performed as described previously. ${ }^{24}$

\section{Oligonucleotide microarray analysis}

Analysis of the expression profile of the IGF-related genes was performed using commercially available oligonucleotide microarrays of HG-U133A (Affymetrix, Santa Clara, CA, USA) in accordance with the manufacturer's recommendations, as described previously. ${ }^{24}$ The oligonucleotide microarray analysis was performed on eight samples out of 29 samples - three samples before and five samples after the ranibizumab intravitreal injections.

\section{Real-time RT-qPCR}

The mRNA level of $I G F 1, I G F 2, I G F 1 R, I G F 2 R$, and b-actin $(A C T B)$ was determined using the real-time quantitative reverse transcription polymerase chain reaction (RT-qPCR). The quantitative analysis was carried out using SYBR Green I chemistry (SYBR Green Quantitect RT-PCR Kit, Qiagen, Valencia, CA, USA) and DNA Engine Opticon ${ }^{\mathrm{TM}}$ System (MJ Research Inc., MA, USA). The oligonucleotide primers and thermal profile have been previously described. ${ }^{25,26}$ The mRNA copy number was recalculated per $1 \mu \mathrm{g}$ of the total RNA.

\section{Statistical analyses}

Analysis of the results obtained from oligonucleotide microarrays was performed using the GeneSpring 13.0 software (Agilent Technologies UK Ltd, South Queensferry, UK) and the Pl-Grid platform. Normalization of the results was performed using the Robust Multi-Array Average method. The differences in the expression levels of the IGFrelated transcripts between the two groups were evaluated using the unpaired $t$-test with a cutoff at least a 1.5 -fold change and $p<0.05$. The real-time RT-qPCR results were subjected to statistical analysis using Statistica 12.0 software (StatSoft, Tulsa, OK, USA), and the Mann-Whitney $U$ test was applied to compare the differences in the expression of $I G F 1, I G F 2, I G F 1 R$, and $I G F 2 R$. The values that were obtained using the real-time RT-qPCR were expressed as medians with the 25 th and 75 th quartiles and minimum and maximum.

\section{Results}

In the first step of the study, 26 ID mRNAs that are associated with the IGF family were selected from the NetAffx Analysis Center database of Affymetrix (http://www.affymetrix. com/analysis/index.affx). Among these, in the patient group receiving ranibizumab in comparison to the patient group before ranibizumab treatment, six statistically significant differentially expressed transcripts were detected (unpaired $t$-test, $p<0.05$, fold change $>1.5$ ) based on the oligonucleotide microarray data analysis (Table 1).

In the next step of the study, comparative analysis of the $I G F 1, I G F 2, I G F 1 R$, and $I G F 2 R$ mRNA copies/ $\mu \mathrm{g}$ of the total RNA was performed between the two groups that were studied using the real-time RT-qPCR technique. Our results revealed statistically significant differences in the $I G F 2$ and $I G F 2 R$ mRNA levels (Mann-Whitney $U$ test, $p=0.017, p=0.023$, respectively). However, there were no statistically significant differences in the IGFI and IGFIR mRNAs (Mann-Whitney $U$ test, $p=0.809, p=0.422$, respectively) (Figure 1A and B).

Table I Characteristics of the IGF family transcripts that exhibit a differential expression in the PBMCs of patients with clinically diagnosed AMD before and after ranibizumab treatment

\begin{tabular}{|c|c|c|c|c|c|c|}
\hline Fold change & Number of ID mRNAs & $\mathbf{p}<0.05$ & $p<0.02$ & $\mathbf{p}<0.0 \mathrm{I}$ & $p<0.005$ & $\mathbf{p}<0.001$ \\
\hline FC all ID mRNAs & 26 & 7 & 5 & 2 & 2 & I \\
\hline $\mathrm{FC}>\mathrm{I} . \mathrm{I}$ & 19 & 7 & 5 & 2 & 2 & I \\
\hline $\mathrm{FC}>\mathrm{I} .5$ & 8 & 6 & 5 & 2 & 2 & I \\
\hline \multirow[t]{2}{*}{ ID mRNA } & \multirow[t]{2}{*}{ Gene symbol } & \multirow{2}{*}{\multicolumn{2}{|c|}{ Gene name }} & & $\mathbf{F C}$ & \multirow[t]{2}{*}{$p$-value } \\
\hline & & & & & after vs before & \\
\hline 20954I_at & IGFI & \multicolumn{2}{|c|}{ Insulin-like growth factor I } & & $2.32 \downarrow$ & 0.0010 \\
\hline 202409_at & IGF2 & \multicolumn{2}{|c|}{ Insulin-like growth factor 2} & & $\mathrm{I} .8 \mathrm{I} \downarrow$ & 0.0188 \\
\hline 213910_at & IGFBP7 & \multicolumn{2}{|c|}{ Insulin-like growth factor binding protein 7} & & $2.54 \downarrow$ & 0.0134 \\
\hline 211959_at & IGFBP5 & \multicolumn{2}{|c|}{ Insulin-like growth factor binding protein 5} & & $2.31 \downarrow$ & 0.0023 \\
\hline 211958_at & IGFBP5 & \multicolumn{2}{|c|}{ Insulin-like growth factor binding protein 5} & & $1.60 \downarrow$ & 0.0498 \\
\hline 210095_s_at & IGFBP3 & \multicolumn{2}{|c|}{ Insulin-like growth factor binding protein 3} & & $2.18 \downarrow$ & 0.0197 \\
\hline
\end{tabular}

Notes: Unpaired t-test, $\downarrow$ - lower expression, differentially expressed genes with $p<0.05$ and FC $>1.5$ are indicated in bold.

Abbreviations: AMD, age-related macular degeneration; FC, fold change; IGF, insulin-like growth factor; PBMC, peripheral blood monoculear cells. 

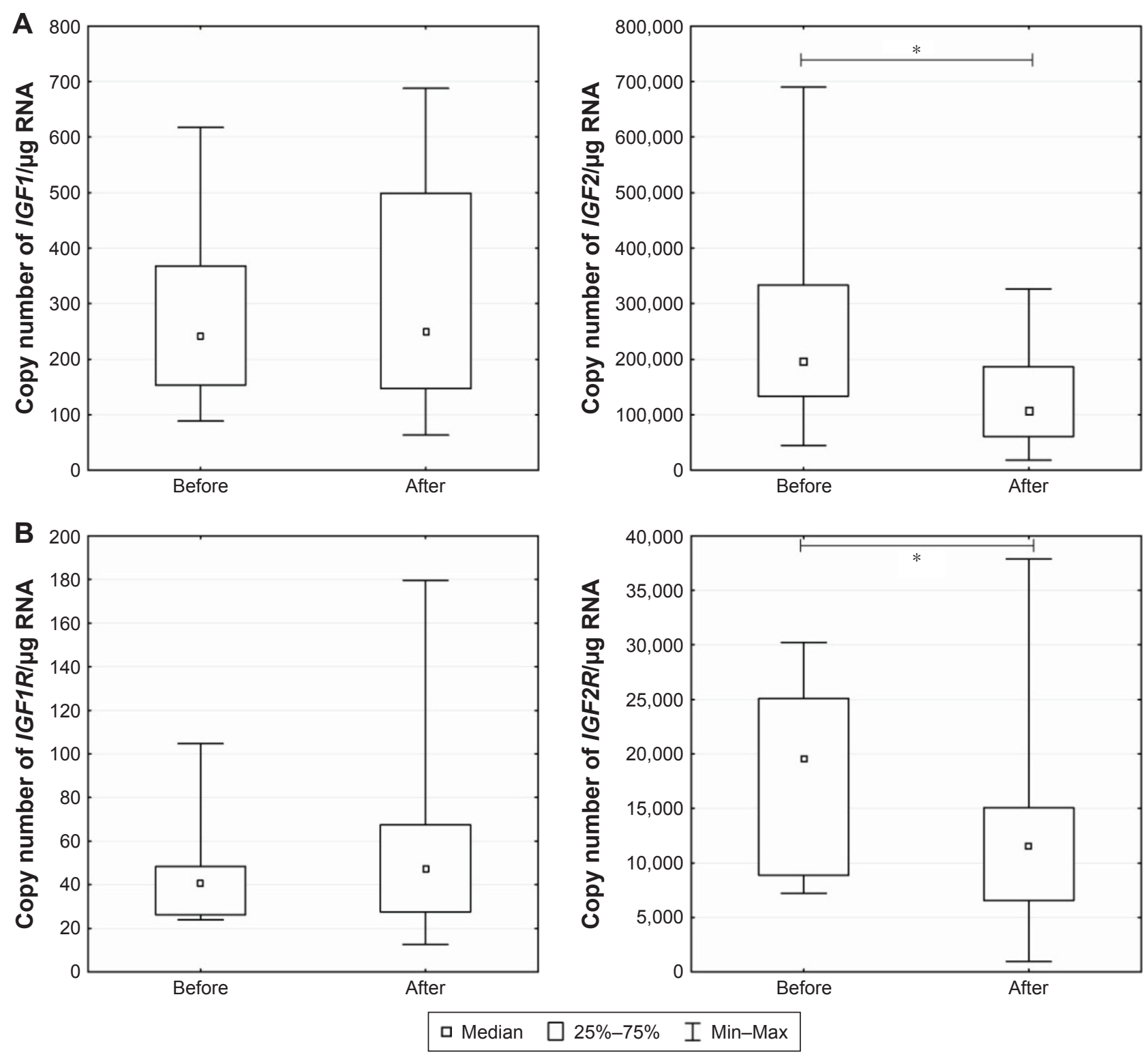

Figure I The mRNA levels of IGFI, IGF2 (A) and IGFIR, IGF2R (B) in the PBMCs of patients with clinically diagnosed AMD before and after ranibizumab treatment. Notes: Box and whisker plots present medians \pm quartiles and extreme values of copy numbers per I $\mu g$ of total RNA. Statistical significance: ${ }^{*} p<0.05$, Mann-Whitney $U$ test. Abbreviations: AMD, age-related macular degeneration; IGF, insulin-like growth factor; PBMC, peripheral blood monoculear cells.

Statistical analyses of both oligonucleotide microarray and real-time RT-qPCR results demonstrated a significant difference in expression only for $I G F 2$ mRNA.

\section{Discussion}

The IGF family plays an important role in the pathogenesis of many diseases, including eye diseases. ${ }^{27}$ Lambooij et al ${ }^{28}$ and Rosenthal et a ${ }^{29}$ suggested its implication in the development of AMD. However, the exact role of IGFs in AMD still needs to be explained. In our study using oligonucleotide microarray, it was revealed that the IGF1,IGF2,IGFBP1, $I G F B P 3$, and $I G F B P 5$ levels were significant downregulated in the PBMCs from patients with AMD after ranibizumab treatment. Microarray analysis enables screening of gene expression profile. However, it is known that RT-qPCR has a higher sensitivity and specificity in comparison to the oligonucleotide microarray. Therefore, our study focused on the use of oligonucleotide microarray to investigate the expression profile of 26 ID mRNAs of IGF-related genes, and then the microarray data were verify using the real-time RT-qPCR technique. Validation of these results revealed statistically significant differences in the $I G F 2$ and $I G F 2 R$ mRNA levels. The differences between microarray and RT-qPCR techniques may also result from carrying out 
RT-qPCR assay on the larger study group. However, both analyses presented statistically significant differences only for IGF2 mRNA. The mRNA level of the studied genes was determined in PBMC samples although, eg, vitreal samples may better reflect the retinal and choroidal conditions. ${ }^{30}$ It is also known that human vitreous IGF2 level is several times higher than IGF1 level. ${ }^{31}$ However, vitreous samples are much harder to obtain than PBMC samples, and this was not possible with our patients.

Although both IGF1 and IGF2 can easily be detected in plasma, ${ }^{32}$ Haurigot et a ${ }^{10}$ showed that an increased intraocular but not systemic level of IGF1 can cause a disruption of blood-retinal barrier (BRB), which leads to various ocular diseases. Moreover, after treatment with IGF1, intravitreally injected, rats developed retinal vascular hyperpermeability that caused the degradation of BRB. These authors also observed an increased expression of VEGF in these rats. ${ }^{33}$ On the other hand, Spranger et $\mathrm{al}^{13}$ reported that an increased systemic expression of IGF1, IGF2, and IGFBP3 in proliferative diabetic retinopathy patients caused the disruption of BRB, which lead to the intravitreal accumulation of IGFs. These authors suggested that this is a more important source of these growth factors than local synthesis. Moreover, Hellstrom et a $1^{35}$ suggested that the IGF1 level can be used to predict whether ROP will develop in premature infants. These authors showed that low serum levels of IGF1 could cause hypoxic retina, which can induce VEGF expression. Previous reports also disclosed that there is a correlation between systemic level of IGFs and the changes in eye structures. ${ }^{36,37}$ The abovementioned studies suggested that the source of elevated level of IGF family in ocular diseases still needs explanation. Moreover, there was revealed a significant correlation between serum and vitreous level of VEGF in proliferative diabetic retinopathy patients. ${ }^{38}$ In turn, Romano et $\mathrm{a}^{39}$ revealed altered expression of three microRNA both in rat retinas and in serum of AMD patients. However, only a few reports showed changed expression of various mRNAs or proteins in PBMCs obtained from AMD patients. ${ }^{40-42}$ Moreover, there are no published data regarding influence of intravitreally injected ranibizumab on IGF family expression level in the blood or vitreous of AMD patients. Previous research revealed only reduced concentration of VEGF after intravitreal ranibizumab treatment in the aqueous humor of AMD patients ${ }^{43}$ or in the vitreous of diabetic proliferative retinopathy patients. ${ }^{44}$ In turn, Manresa et a ${ }^{45}$ showed no significant differences in homocysteine level after ranibizumab injections in the plasma and vitreous obtained from patients with AMD. Kong et $\mathrm{al}^{23}$ measured the serum level of IGF1 and VEGF in infants with ROP, but after intravitreal bevacizumab injections. These authors revealed decreased serum levels of both of the growth factors 2 days after treatment. However, after this time, the IGF1 level was increased, but it was always lower than in infants who had been treated with laser. In this case, a lower level of IGF1 after bevacizumab treatment may cause slower vessel maturation than in the laser-treated infants. On the other hand, Hong et $\mathrm{al}^{46}$ and $\mathrm{Wu}$ et $\mathrm{al}{ }^{47}$ revealed a decreased serum level of VEGF after bevacizumab treatment although other growth factors, including IGF1, were unchanged in infants with ROP. In our results, a decreased expression of IGF-related genes after anti-VEGF treatment was observed but in the PBMCs from the AMD patients who had been treated with ranibizumab. This is consistent with other results which showed that intravitreally injected anti-VEGF agents can be detected in serum/PBMCs and can therefore have a systemic influence. ${ }^{19,24}$ Moreover, some reports demonstrated the potential systemic effects of anti-VEGF therapy for AMD, ${ }^{20,24,48} \mathrm{eg}$, in our previous studies mean central retinal thickness was reduced in the treated eyes after intravitreal ranibuzumab injections. In addition, central retinal thickness was also decreased in the fellow eyes. ${ }^{24}$ On the other hand, subfoveal choroidal thickness and foveal thickness were increased in patients with controlled acromegaly. ${ }^{49}$ Moreover, Yazgan et el ${ }^{37}$ showed positive correlation between macular choroidal thickness and serum IGF1 level. In turn, Polat et al ${ }^{50}$ revealed no significant difference in mean central retinal thickness between the patients with acromegaly and the control group. However, retinal neovascularization was decreased after systemic inhibition of growth hormone or IGF1 in mice. ${ }^{36}$

Neovascularization can also be promoted by IGF $2 .{ }^{51}$ Kim et a ${ }^{52}$ reported that hypoxia induces $I G F 2$ expression and then retinal vascularization during ocular development. In turn, Spranger et $\mathrm{a}^{34}$ detected IGF1, IGF2, and IGFBP3 in both the serum and vitreous in patients with proliferative diabetic retinopathy. These authors suggested that there is a possibility to treat this disease using inhibitors of the systemic IGF levels. These results are supported by Dransfield et al's ${ }^{53}$ study which showed that the human monoclonal antibody against IGF2 can cause the inhibition of cancer cells both in vitro and in vivo. Maeng et a ${ }^{54}$ also suggested that IGF2 could be a target for the treatment of diseases that are connected with neovascularization. It is also known that VEGF can decrease the expression of IGFBP3 and increase IGFBP5 at both the protein and mRNA levels in bovine aortic endothelial cells. ${ }^{55}$ Moreover, in diabetic human retinal endothelial cells, IGF1R, IGFBP1, IGFBP2, 
IGFBP3, and IGFBP5 were increased at the protein level and $I G F B P 1, I G F B P 2$, and $I G F B P 5$ also were increased at the mRNA level, while the IGFIR and IGFBP3 expression was unchanged. ${ }^{56}$

IGFBP1 can inhibit IGF1 and IGF2. ${ }^{51}$ In turn, IGFBP3 plays different roles. Some reports revealed that it can play an antiapoptotic role and that it can stimulate angiogenesis, but other reports showed that IGFBP3 could inhibit angiogenesis and counteract the effect of VEGF ${ }^{27}$ Although an increased level of IGF1 in vitreous proliferative diabetic retinopathy is seen, the IGFBP1 and IGFBP3 levels were unchanged. ${ }^{57}$ In turn, infants with ROP had a lower plasma IGFBP3 level. ${ }^{58}$ Similarly, it is known that IGFBP5 and IGFBP6 also have an inhibitory effect on IGFs. ${ }^{51}$ Some of these proteins can act through IGF-independent mechanisms. ${ }^{27}$ Moreover, retinas in a hypoxia condition showed a decreased expression of IGFBP7 compared to retinas in a normal condition. ${ }^{13}$ Lofqvist et $\mathrm{al}^{59}$ detected a greater expression of IGF2 than IGF1 in the photoreceptors and blood vessels of mouse retina. Moreover, these authors also observed an increased expression of $I G F B P 3, I G F B P 5$, and IGFBP7 in the pathological vessels compared to normal vessels.

Jacobo et $\mathrm{al}^{60}$ performed studies about the influence of the single-nucleotide polymorphisms of the HTRAl gene. The product of this changed gene cannot bind to IGF1 and therefore causes an amelioration of the effects of IGF1. These authors suggested that the polymorphisms of this gene can cause the development of AMD. In turn, Chiu et $\mathrm{al}^{12}$ showed that a single-nucleotide polymorphism in $I G F 1 R$ is connected with a greater risk of the development of AMD. Makarev et $\mathrm{al}^{61}$ performed an analysis of the pathway development and revealed a differential expression of 29 pathways in AMD, including the proangiogenic proliferation pathways, eg, those connected with IGF2. Moreover, Newman et al ${ }^{62}$ performed transcriptome analysis in choroid-RPE and retina tissue samples that had been obtained from AMD and control subjects. These authors suggested that IGF2 could be a target for AMD treatment. Cha et al, ${ }^{63}$ who performed an analysis of the cytokine concentration in the aqueous humor that had been collected from patients with neovascular AMD, provided important information. These authors found a statistically significant higher level of IGF1, IGFBP2, IGFBP6, and IGBP7 in the aqueous humor of patients who had been diagnosed with exudative AMD, thereby indicating their involvement in angiogenesis.

Dong et $\mathrm{l}^{64}$ revealed that the polypyrimidine tract-binding protein-associated splicing factor can inhibit VEGF expression stimulated by IGF. Shaw et $\mathrm{l}^{65}$ suggested that the IGF1 receptor ribozyme could reduce retinal neovascularization. In turn, Lee et $\mathrm{al}^{66}$ showed that an extract of Cinidium officinale Makino and its bioactive compound, butylidenephthalide, could be used in the treatment of AMD because they inhibit IGFBP1, MCP1 and VEGF expression. Deissler et $\mathrm{a}^{67}$ revealed that ranibizumab can inhibit the migration of the bovine retinal endothelial cells that are induced by VEGF, IGF, PGF, and FGF2. On the other hand, Shao et $\mathrm{a}^{68}{ }^{6}$ showed an upregulation of IGF1 both at the mRNA and protein level after bevacizumab treatment, but in xenografts that had been derived from ovarian cancer cell lines.

\section{Conclusion}

Our study indicated a differential gene expression of IGF2 in PBMCs obtained from AMD patients before and after the intravitreal ranibizumab treatment. However, additional studies are needed to confirm our results conclusively, but this study may provide a valuable basis for further research that will be carried out on a larger group of patients.

\section{Acknowledgment}

This research was supported in part by PL-Grid Infrastructure.

\section{Disclosure}

The authors report no conflicts of interest in this work.

\section{References}

1. De Jong PT. Age-related macular degeneration. N Engl J Med. 2006; 355(14):1474-1485.

2. Congdon N, O'Colmain B, Klaver CC, et al. Causes and prevalence of visual impairment among adults in the United States. Arch Ophthalmol. 2004;122(4):477-485.

3. Buch H, Vinding T, La Cour M, Appleyard M, Jensen GB, Nielsen NV. Prevalence and causes of visual impairment and blindness among 9980 Scandinavian adults: the Copenhagen City eye study. Ophthalmology. 2004;111(1):53-61.

4. Maberley DA, Hollands H, Chuo J, et al. The prevalence of low vision and blindness in Canada. Eye (Lond). 2006;20(3):341-346.

5. Wong TY, Chakravarthy U, Klein R, et al. The natural history and prognosis of neovascular age-related macular degeneration: a systematic review of the literature and meta-analysis. Ophthalmology. 2008; 115(1):116-126.

6. Chiu CJ, Taylor A. Nutritional antioxidants and age-related cataract and maculopathy. Exp Eye Res. 2007;84(2):229-245.

7. Haddad S, Chen CA, Santangelo SL, Seddon JM. The genetics of age-related macular degeneration: a review of progress to date. Surv Ophthalmol. 2006;51(4):316-363.

8. Wilkinson-Berka JL, Wraight C, Werther G. The role of growth hormone, insulin-like growth factor and somatostatin in diabetic retinopathy. Curr Med Chem. 2006;13:3307-3317.

9. van Beijnum JR, Pieters W, Nowak-Sliwinska P, Griffioen AW. Insulinlike growth factor axis targeting in cancer and tumour angiogenesis - the missing link. Biol Rev Camb Philos Soc. 2017;92(3):1755-1768.

10. Haurigot $\mathrm{V}$, Villacampa $P$, Ribera $A$, et al. Increased intraocular insulinlike growth factor-I triggers blood-retinal barrier breakdown. J Biol Chem. 2009;284(34):22961-22969. 
11. Fürstenberger G, Senn HJ. Insulin-like growth factors and cancer. Lancet Oncol. 2002;3(5):298-302.

12. Chiu CJ, Conley YP, Gorin MB, et al. Associations between genetic polymorphisms of insulin like growth factor axis genes and risk for age-related macular degeneration. Invest Ophthalmol Vis Sci. 2011;52(12):9099-9107.

13. Nguyen DV, Li Calzi S, Shaw LC, Kielczewski JL, Korah HE, Grant MB. An ocular view of the IGF-IGFBP system. Growth Horm IGF Res. 2013;23(3):45-52.

14. Rajpathak SN, Gunter MJ, Wylie-Rosett J, et al. The role of insulin like growth factor-I and its binding proteins in glucose homeostasis and type 2 diabetes. Diabetes Metab Res Rev. 2009;25(1):3-12.

15. Bloch SB, la Cour M, Sander B, et al. Predictors of 1-year visual outcome in neovascular age-related macular degeneration following intravitreal ranibizumab treatment. Acta Ophthalmol. 2013; 91(1):42-47.

16. Huang J, Chen T, Lu Y, Long L, Dai H. Retinoschisis and intravitreal ranibizumab treatment for myopic choroidal neovascularization. Chin Med J (Engl). 2014;127(11):2053-2057.

17. Yang X, Dai H. Intravitreal ranibizumab for the treatment of pathological myopia associated with choroidal neovascularization in Chinese patients. Chin Med J (Engl). 2014;127(16):2906-2910.

18. Droege KM, Caramoy A, Kersten A, et al. Patient preference of ranibizumab treatment regimen for neovascular age-related macular degeneration - monthly injections versus pro re nata. Graefes Arch Clin Exp Ophthalmol. 2014;252(1):31-34.

19. Lim LS, Cheung CM, Mitchell P, Wong TY. Emerging evidence concerning systemic safety of anti-VEGF agents - should ophthalmologists be concerned? Am J Ophthalmol. 2011;152(3):329-331.

20. Nassar K, Grisanti S, Elfar E, Lüke J, Lüke M, Grisanti S. Serum cytokines as biomarkers for age-related macular degeneration. Graefes Arch Clin Exp Ophthalmol. 2015;253(5):699-704.

21. Nita M, Michalska-Małecka K, Mazurek U, et al. Influence of ranibizumab treatment on the extracellular matrix in patients with neovascular age-related macular degeneration. Med Sci Monit. 2014;20: 875-883.

22. Falk MK, Singh A, Faber C, Nissen MH, Hviid T, Sørensen TL. Blood expression levels of chemokine receptor CCR3 and chemokine CCL11 in age-related macular degeneration: a case-control study. BMC Ophthalmol. 2014;14:22.

23. Kong L, Bhatt AR, Demny AB, et al. Pharmacokinetics of bevacizumab and its effects on serum VEGF and IGF-1 in infants with retinopathy of prematurity. Invest Ophthalmol Vis Sci. 2015;56(2): 956-961.

24. Michalska-Małecka K, Kabiesz A, Kimsa MW, et al. Effects of intravitreal ranibizumab on the untreated eye and systemic gene expression profile in age-related macular degeneration. Clin Interv Aging. 2016;11:357-365.

25. Braczkowski R, Białożyt M, Plato M, Mazurek U, Braczkowska B. Expression of insulin-like growth factor family genes in clear cell renal cell carcinoma. Contemp Oncol (Pozn). 2016;20(2):130-136.

26. Romaniuk D, Kimsa MW, Strzałka-Mrozik B, et al. Gene expression of IGF1, IGF1R and IGFBP3 in epiretinal membranes of patients with proliferative diabetic retinopathy: Preliminary study. Mediators Inflamm. 2013;2013:986217.

27. Bach LA. Endothelial cells and the IGF system. J Mol Endocrinol. 2015;54(1):1-13.

28. Lambooij AC, van Wely KH, Lindenbergh-Kortleve DJ, Kuijpers RW, Kliffen M, Mooy CM. Insulin-like growth factor-I and its receptor in neovascular age-related macular degeneration. Invest Ophthalmol Vis Sci. 2003;44(5):2192-2198.

29. Rosenthal R, Wohlleben H, Malek G, et al. Insulin-like growth factor-1 contributes to neovascularization in age-related macular degeneration. Biochem Biophys Res Commun. 2004;323(4):1203-1208.

30. Ecker SM, Hines JC, Pfahler SM, Glaser BM. Aqueous cytokine and growth factor levels do not reliably reflect those levels found in the vitreous. Mol Vis. 2011;17:2856-2863.
31. Meyer-Schwickerath R, Pfeiffer A, Blum WF, et al. Vitreous levels of the insulin-like growth factors I and II, and the insulin-like growth factor binding proteins 2 and 3, increase in neovascular eye disease. Studies in nondiabetic and diabetic subjects. J Clin Invest. 1993;92(6): $2620-2625$.

32. Bergman D, Halje M, Nordin M, Engström W. Insulin-like growth factor 2 in development and disease: a mini-review. Gerontology. 2013;59(3): 240-249.

33. Zhang SX, Ma JX, Sima J, et al. Genetic difference in susceptibility to the blood-retina barrier breakdown in diabetes and oxygen-induced retinopathy. Am J Pathol. 2005;166(1):313-321.

34. Spranger J, Bühnen J, Jansen V, et al. Systemic levels contribute significantly to increased intraocular IGF-I, IGF-II and IGF-BP3 [correction of IFG-BP3] in proliferative diabetic retinopathy. Horm Metab Res. 2000;32(5):196-200.

35. Hellstrom A, Perruzzi C, Ju M, et al. Low IGF-I suppresses VEGFsurvival signaling in retinal endothelial cells: direct correlation with clinical retinopathy of prematurity. Proc Natl Acad Sci U S A. 2001; 98(10):5804-5808.

36. Smith LE, Kopchick JJ, Chen W, et al. Essential role of growth hormone in ischemia-induced retinal neovascularization. Science. 1997;276(5319):1706-1709.

37. Yazgan S, Arpaci D, Celik HU, Isik I. Evaluation of macular and peripapillary choroidal thickness, macular volume and retinal nerve fiber layer in acromegaly patients. Int Ophthalmol. Epub 2017 May 15.

38. Baharivand N, Zarghami N, Panahi F, Dokht Ghafari MY, Mahdavi Fard A, Mohajeri A. Relationship between vitreous and serum vascular endothelial growth factor levels, control of diabetes and microalbuminuria in proliferative diabetic retinopathy. Clin Ophthalmol. 2012; 6:185-191.

39. Romano GL, Platania CBM, Drago F, et al. Retinal and circulating miRNAs in age-related macular degeneration: an in vivo animal and human study. Front Pharmacol. 2017;8:168.

40. Lechner J, Chen M, Hogg RE, et al. Peripheral blood mononuclear cells from neovascular age-related macular degeneration patients produce higher levels of chemokines CCL2 (MCP-1) and CXCL8 (IL-8). J Neuroinflammation. 2017;14(1):42.

41. Zhu Y, Liang L, Qian D, et al. Increase in peripheral blood mononuclear cell Toll-like receptor $2 / 3$ expression and reactivity to their ligands in a cohort of patients with wet age-related macular degeneration. Mol Vis. 2013;19:1826-1833.

42. Liu XX, Yao ZM. Insensitivity of PI3K/Akt/GSK3 signaling in peripheral blood mononuclear cells of age-related macular degeneration patients. J Biomed Res. Epub 2017 Jan 19.

43. Sawada O, Miyake T, Kakinoki M, Sawada T, Kawamura H, Ohji M. Aqueous vascular endothelial growth factor after intravitreal injection of pegaptanib or ranibizumab in patients with age-related macular degeneration. Retina. 2010;30(7):1034-1038.

44. Yan Y, Zhu L, Hong L, Deng J, Song Y, Chen X. The impact of ranibizumab on the level of intercellular adhesion molecule type 1 in the vitreous of eyes with proliferative diabetic retinopathy. Acta Ophthalmol. 2016;94(4):358-364.

45. Manresa N, Mulero J, Losada M, Zafrilla P. Effect of pegaptanib and ranibizumab on plasma and vitreous homocysteine in patients with exudative age-related macular degeneration. Retina. 2015;35(9): $1765-1771$.

46. Hong YR, Kim YH, Kim SY, Nam GY, Cheon HJ, Lee SJ. Plasma concentrations of vascular endothelial growth factor in retinopathy of prematurity after intravitreal bevacizumab injection. Retina. 2015;35(9): $1772-1777$.

47. Wu WC, Lien R, Liao PJ, et al. Serum levels of vascular endothelial growth factor and related factors after intravitreous bevacizumab injection for retinopathy of prematurity. JAMA Ophthalmol. 2015;133(4): 391-397.

48. Wu Z, Sadda SR. Effects on the contralateral eye after intravitreal bevacizumab and ranibizumab injections: a case report. Ann Acad Med Singapore. 2008;37(7):591-593. 
49. Pekel G, Akin F, Ertürk MS, et al. Chorio-retinal thickness measurements in patients with acromegaly. Eye (Lond). 2014;28(11):1350-1354.

50. Polat SB, Ugurlu N, Ersoy R, Oguz O, Duru N, Cakir B. Evaluation of central corneal and central retinal thicknesses and intraocular pressure in acromegaly patients. Pituitary. 2014;17(4):327-332.

51. Chao W, D'Amore PA. IGF2: epigenetic regulation and role in development and disease. Cytokine Growth Factor Rev. 2008;19(2):111-120.

52. Kim JH, Park SW, Yu YS, Kim KW, Kim JH. Hypoxia-induced insulinlike growth factor II contributes to retinal vascularization in ocular development. Biochimie. 2012;94(3):734-740.

53. Dransfield DT, Cohen EH, Chang Q, et al. A human monoclonal antibody against insulin-like growth factor-II blocks the growth of human hepatocellular carcinoma cell lines in vitro and in vivo. Mol Cancer Ther. 2010;9(6):1809-1819.

54. Maeng YS, Choi HJ, Kwon JY, et al. Endothelial progenitor cell homing: prominent role of the IGF2-IGF2R-PLCbeta2 axis. Blood. 2009;113(1):233-243.

55. Dahlfors G, Arnqvist HJ. Vascular endothelial growth factor and transforming growth factor-beta 1 regulate the expression of insulin-like growth factor-binding protein-3, -4 and -5 in large vessel endothelial cells. Endocrinology. 2000;141(6):2062-2067.

56. Spoerri PE, Ellis EA, Tarnuzzer RW, Grant MB. Insulin-like growth factor: receptor and binding proteins in human retinal endothelial cell cultures of diabetic and non-diabetic origin. Growth Horm IGF Res. 1998;8(2):125-132.

57. Burgos R, Mateo C, Cantón A, Hernández C, Mesa J, Simó R. Vitreous levels of IGF-I, IGF binding protein 1 and IGF binding protein 3 in proliferative diabetic retinopathy. Diabetes Care. 2000;23(1):80-83.

58. Gharehbaghi MM, Peirovifar A, Sadeghi K, Mostafidi H. Insulin-like growth factor binding protein-3 in preterm infants with retinopathy of prematurity. Indian J Ophthalmol. 2012;60(6):527-530.

59. Lofqvist C, Willett KL, Aspegren O, et al. Quantification and localization of the IGF/insulin system expression in retinal blood vessels and neurons during oxygen-induced retinopathy in mice. Invest Ophthalmol Vis Sci. 2009;50(4):1831-1837.
60. Jacobo SM, Deangelis MM, Kim IK, Kazlauskas A. Age-related macular degeneration-associated silent polymorphisms in HtrA1 impair its ability to antagonize insulin-like growth factor 1. Mol Cell Biol. 2013;33(10):1976-1990.

61. Makarev E, Cantor C, Zhavoronkov A, Buzdin A, Aliper A, Csoka AB. Pathway activation profiling reveals new insights into age-related macular degeneration and provides avenues for therapeutic interventions. Aging (Albany NY). 2014;6(12):1064-1075.

62. Newman AM, Gallo NB, Hancox LS, et al. Systems-level analysis of age-related macular degeneration reveals global biomarkers and phenotype-specific functional networks. Genome Med. 2012;4(2):16.

63. Cha DM, Woo SJ, Kim HJ, Lee C, Park KH. Comparative analysis of aqueous humor cytokine levels between patients with exudative agerelated macular degeneration and normal controls. Invest Ophthalmol Vis Sci. 2013;54(10):7038-7044.

64. Dong L, Nian H, Shao Y, et al. PTB-associated splicing factor inhibits IGF-1-induced VEGF upregulation in a mouse model of oxygeninduced retinopathy. Cell Tissue Res. 2015;360(2):233-243.

65. Shaw LC, Pan H, Afzal A, et al. Proliferating endothelial cell-specific expression of IGF-I receptor ribozyme inhibits retinal neovascularization. Gene Ther. 2006;13(9):752-760.

66. Lee YM, Lee YR, Kim JS, Kim YH, Kim J. Cinidium officinale and its bioactive compound, butylidenephthalide, inhibit laser-induced choroidal neovascularization in a rat model. Molecules. 2015;20(11): 20699-20708.

67. Deissler HL, Deissler H, Lang GK, Lang GE. Ranibizumab efficiently blocks migration but not proliferation induced by growth factor combinations including VEGF in retinal endothelial cells. Graefes Arch Clin Exp Ophthalmol. 2013;251(10):2345-2353.

68. Shao M, Hollar S, Chambliss D, et al. Targeting the insulin growth factor and the vascular endothelial growth factor pathways in ovarian cancer. Mol Cancer Ther. 2012;11(7):1576-1586.
Clinical Interventions in Aging

\section{Publish your work in this journal}

Clinical Interventions in Aging is an international, peer-reviewed journal focusing on evidence-based reports on the value or lack thereof of treatments intended to prevent or delay the onset of maladaptive correlates of aging in human beings. This journal is indexed on PubMed Central, MedLine,

\section{Dovepress}

CAS, Scopus and the Elsevier Bibliographic databases. The manuscript management system is completely online and includes a very quick and fair peer-review system, which is all easy to use. Visit http://www.dovepress. com/testimonials.php to read real quotes from published authors. 